\title{
Social network analysis in innovation research: using a mixed methods approach to analyze social innovations
}

\author{
Nina Kolleck
}

Received: 29 July 2013 / Accepted: 24 September 2013 /Published online: 20 October 2013

(C) The Author(s) 2013. This article is published with open access at Springerlink.com

\begin{abstract}
The importance of social networks for innovation diffusion and processes of social change is widely recognized in many areas of practice and scientific disciplines. Social networks have the potential to influence learning processes, provide opportunities for problem-solving, and establish new ideas. Thus, they can foster synergy effects, bring together key resources such as know-how of participating actors, and promote innovation diffusion. There is wide agreement regarding the usefulness of empirical methods of Social Network Analysis (SNA) for innovation and futures research. Even so, studies that show the chances of implementing SNA in these fields are still missing. This contribution addresses the research gap by exploring the opportunities of a mixed methods SNA approach for innovation research. It introduces empirical results of the author's own quantitative and qualitative investigations that concentrate on five different innovation networks in the field of Education for Sustainable Development.
\end{abstract}

Keywords Social network analysis · Social innovations · Education for sustainable development $\cdot$ Egocentric network maps · Governance

\section{Introduction}

Scholars interested in innovation processes and futures research have often stressed the importance of social networks.

I thank the editors and two anonymous reviewers for their constructive comments, which helped me to improve the article. The article is based on results of a study I conducted at the Freie Universität Berlin. I would also like to thank Gerhard de Haan for useful information and for supporting my research.

N. Kolleck $(\bowtie)$

Universität Heidelberg \& Hertie School of Governance,

Friedrichstraße 180, 10117 Berlin, Germany

e-mail:kolleck@hertie-school.org
Social networks are seen as an important factor in how ideas, norms, and innovations are realized. Social network research understands individuals within their social context, acknowledging the influence of relationships with others on one's behavior. Hence, social networks can promote innovation processes and expand opportunities for learning. Despite the consensus regarding the value of social network approaches, there is a lack of empirical investigations in innovation and futures studies that use Social Network Analysis (SNA). In most cases, the scientific literature uses the concept of social networks metaphorically, ignoring the chances presented by SNA methods. At the same time, conventional empirical research in innovation and futures studies often disregards relational information. Hence, analyses of statistical data on structural and individual levels are treated as separately. Activities that are expected to have impacts on future developments are usually modeled as isolated individual or group behavior, on the one hand, or as the characteristics of structural issues, on the other hand. SNA provides us with empirical tools that capture the social context and help to better understand how innovations are implemented and diffused and why social change takes place. Network approaches explicitly challenge the difference between deduction and induction and highlight the relevance of relationships. Individuals both shape and are shaped by the social context in which they interact. By applying techniques of SNA, actor-centered and structuralist reductions are avoided. Instead, SNA emphasizes the mutual influence of structure and social connections. In order to better understand and model developments in innovation and futures research, relational data inherent to the social network perspective is needed.

This contribution addresses the opportunities of SNA for innovation research. It is divided into six sections. After this introduction, the second section briefly defines crucial concepts of SNA and provides theoretical 
background. The third section discusses the value of a social network perspective for innovation research. The methodological approach, along with the empirical case studies used, is outlined in the fourth section. The fifth section shows how a combination of both insights from structure based on quantitative SNA and subjective perceptions revealed with qualitative SNA is helpful for understanding innovation processes. Here, the integration of qualitative SNA such as egocentric network maps in quantitative techniques of SNA is illustrated. The contribution concludes with a summary of main arguments.

\section{Theoretical and methodological background}

While in the scientific literature there are diverse understandings on what a social network is, this contribution draws on the definition used by Stanley Wassermann and Katherine Faust:

"A social network consists of a finite set or sets of actors and the relation or relations defined on them. The presence of relational information is a critical and defining feature of a social network" [1].

This conception of social network permits both a governance approach and empirical techniques of SNA. Scholars of governance research understand social networks as a certain type of governance that can be differentiated from other ideal types of governance: markets and hierarchies. Social networks combine market-based and hierarchic dimensions and serve as a form of hybrid governance [2]. Both weak and strong modes of coordination are integrated into the network concept of governance research, where strong coordination is defined as "the spectrum of activity in which one party alters its own ... strategies to accommodate the activity of others in pursuit of a similar goal" [3]. Weak coordination, on the other hand, takes place when actors observe each other's behavior, "and then alter their actions to make their ... strategies complementary with respect to a common goal" [3].

Because they promote constant exchange and deliberation, social networks have strong potential to promote ideological or structural changes and to generate new knowledge. Hence, network governance is not reduced to governmental action, but refers to the search for collective and participative problem-solving strategies and the promotion of innovations. ${ }^{1}$

\footnotetext{
${ }^{1}$ At the same time, there is little research on the democratic implications of network governance [5] as well as on the strengths and limits of the concept related to issues of educational innovations such as Education for Sustainable Development (ESD).
}

This article uses the concept of network governance to highlight the relevance of relationships for innovation research. Hence, it confronts the assumption that individual behavior is independent of any others, but instead conceives "problem-solving as a collaborative effort in which a network of actors, including both state and non-state organizations, play a part" [4]. ${ }^{2}$

In order to better understand the opportunities of SNA for innovation research, this contribution introduces innovation networks in five different regions as case studies. Innovation networks are understood as social networks that aim at establishing a social innovation. Here, the social innovation of Education for Sustainable Development (ESD) is used. At the same time, the term social innovation refers to processes of implementing and diffusing new social concepts across different sectors of society. While "innovation" implies a kind of renewal, "social" connotes interaction of actors. Social innovations have a direct connection with the search for solutions to social problems and challenges [6, 7]. Likewise, Education for Sustainable Development can be defined as education that empowers people to foresee, try to understand, and solve the problems that threaten life on our planet. With the goal of promoting behavioral changes that will shape a more sustainable future, ESD integrates principles of sustainable development into all aspects of education and learning.

\section{Change and innovation through social relations}

How can social networks evoke changes and what are the opportunities for SNA to promote innovation processes? SNA has the potential to overcome uncertainties related to innovation processes. The chance of an innovation gaining acceptance increase significantly if it is supported by interconnected actors rather than singular individuals. Social networks foster change processes and promote innovation diffusion. SNA techniques thus help to understand existing networks and to identify innovation potentials in order to generate new information and reveal options for structural developments. SNA has the capacity to promote innovation processes by dealing with the following issues:

\footnotetext{
${ }^{2}$ When examined through the framework of Social Network Analysis (SNA), the deficits of the concept of 'Educational Governance' become evident. In the scientific literature and in educational and political praxis, the concept of Educational Governance is often exclusively related to institutions of formal learning such as schools or educational training. In this manner, it is not possible to capture the real boundaries of social networks and to conceptualize social networks as can be done with SNA techniques. Furthermore, many actors, initiatives, and activities that play an important role in learning processes are analytically excluded in current applications of Educational Governance. For that reason, this article does not use an Educational Governance approach. Instead, it uses a governance approach that draws on theoretical concepts developed in social science.
} 
- Identification of innovation networks (existing, missing, possible, and realistic cooperation) and investigation of actors, structures, and network boundaries:

By using SNA methods, network structures were determined in previously defined fields. Thus, techniques of egocentric SNA provide us with necessary information with respect to network membership and structural interconnections between actors. Structural properties detected in the context of this project are, for example, centrality, prestige, or weak and strong ties.

- Innovation potentials through network development strategies:

Looking at network structures not only fosters the development and diffusion of new ideas. It can also reveal where and how structural conditions enable innovations and development processes. Furthermore, Social Network Analyses disclose where and how cooperation can be optimized and where and how alterations are possible and reasonable. Presenting stakeholders the results of SNA can foster structural changes.

- Identification and promotion of coordination, information, and motivation:

Analysis of social networks provides us with useful insights into knowledge transfer processes, showing where they exist and how "well" they function. Also, problems of coordination, information, and motivation become evident, providing us with knowledge related to development potentials.

- Development of strategies to reduce uncertainties related to innovation processes:

The costs of information exchange are not only material (money, time), but also social. Uncertainties, lack of confidence, and the fear of a loss of reputation can prevent actors from sharing information and knowledge. Results of SNA help us to identify weaknesses in the knowledge transfer process.

\section{Social network analysis in innovation research}

In order to illustrate the key opportunities of SNA in innovation research, this section draws on the author's own empirical investigations that used a mixed methods approach based on quantitative and qualitative SNA. Data on network members was drawn from five different German municipalities and included initiatives, institutions, thematic groups, and individuals engaged in the field of ESD. The municipalities studied are Alheim, Erfurt, Frankfurt am Main, Gelsenkirchen, and Minden. These municipalities have been awarded by the United Nations Decade of Education for Sustainable Development (UNDESD), 2005-2014, and are characterized by active networks in the field of the social innovation of ESD. Organizations, initiatives, and actors from different sectors of non-formal, informal, and formal education seek to further establish and diffuse the concept of ESD worldwide. Thus, networks within these municipalities can be regarded as best practices concerning their performance in the area of ESD. It should be taken into account, however, that the social networks analyzed here are neither institutionalized nor formally established organizations. Instead, every person engaged in the field of the social innovation is regarded as part of the network to be analyzed. Hence, defining the network boundaries was an important part of the empirical investigation.

The research design included three main steps. First, qualitative data was collected in order to gain a better understanding of the object of research and generate research hypotheses. Second, quantitative SNA was conducted, using both egocentric SNA and complete SNA techniques. Network membership and network boundaries were defined by mixed-mode egocentric SNA. In a first step, a 12-page questionnaire was sent to all persons in each of the five municipalities listed in the data base of the UNDESD. In a second step, all persons from different sectors named more than once were also approached with the questionnaire [8-10]. Referring to Fischer [11] and Burt [12, 13], a name generator was used which allowed to name all relevant persons in the field of ESD. In this way, nodes were only included if they were mentioned more than once by an interviewee in the field of ESD.

The questionnaire first asked respondents to mark people in their ESD network, defined by efforts to contact, cooperation, collaboration, problem-solving, and idea exchange. Respondents were also asked to assess the quality and contact frequency for each relation mentioned and to name those persons with whom the interviewee cooperated especially closely or had established high levels of trust. They were then requested to score their named connections' impact and the relevance with respect to the diffusion of information and the implementation of ESD. Finally, the questionnaire included questions on future prospects, desires, and developmental possibilities.

Egocentric network data was aggregated in order to enable applications of complete SNA. The (strictly adjusted) dataset of the whole network of all five municipalities consists of 1,306 persons and 2,195 edges. Subsequent to the quantitative studies, qualitative network maps were created in order to gain deeper insights into the qualitative characteristics of the networks' structural properties. ${ }^{3}$ This article focuses mainly on results from the second and the third part of the data analysis.

\footnotetext{
${ }^{3}$ Qualitative network maps were gathered in cooperation with a research project coordinated by Inka Bormann.
} 


\section{Insights from structures and individuals: engaging top-down and bottom-up approaches}

Empirical results were visualized drawing back on UCINET, Netdraw, and Pajek in order to provide a comprehensive foundation for stakeholders [14, 15]. Top-down visualizations of network data were used to generate courses of action, guidance, and network management strategies with the persons involved in the process. Thus, network visualizations and empirical insights enabled stakeholders to detect weaknesses related to structural issues, information flows, and communication problems.

In order to visualize the networks, directional relations between network members were entered into UCINET and mapped with Netdraw. The iterative method of "spring embedding" was chosen for the graph-theoretic layout, because it supports neat illustrations of data sets. Thus, the lengths of the ties do not have information content. The nodes in network visualizations represent persons engaged in implementing ESD in their municipalities. Against the backdrop of the definition of network boundaries, persons that are represented by nodes with only one ingoing link and no outgoing link were not interviewed.

To give an example, one surprising result was the low level of cooperation beyond municipal borders, as measured by network connections, as seen in Fig. 1.
In contrast to Manuel Castells [16], who observed a diminishing relevance of space due to the information age, the present study finds that space remains a constraint for diffusion of ESD. It seems much easier to establish the social innovation ESD in the local context with dense network structures and to subsequently foster its diffusion through weak ties $[17,18]$.

Furthermore, municipal stakeholders were confronted with the unexpected existence of many structural holes and brokerage positions. The concepts "brokerage" and "structural hole" refer to actors' structural embeddedness. A person who maintains connections with people, who do themselves not become interconnected, has the ability to mediate between these contacts and to obtain benefits from his brokerage position [19-21]. At the same time, structural holes impede innovation processes and information flows.

Figures 2 and 3 take Erfurt and Gelsenkirchen as examples and show relations regarding to the question of who is contacted to develop new ideas related to ESD. Only those relationships with a contact frequency of at least once a month are represented in this figure. The ESD network of Erfurt is chosen as an extreme example, because the structure of its social network exhibits the highest number of structural holes.

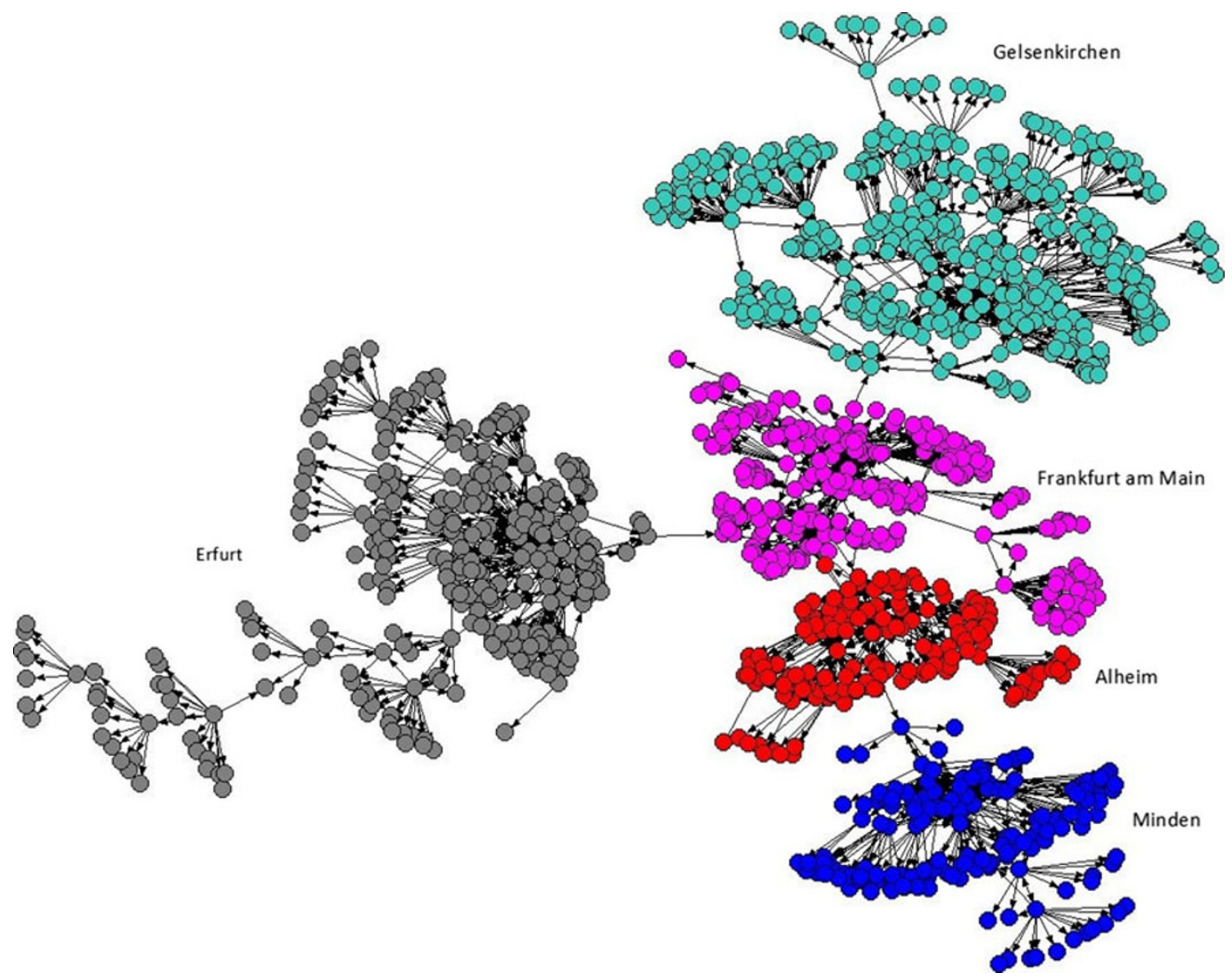

Fig. 1 Trans-regional ESD network, generated with the graph theoretical layout spring embedding, source: Author's data 


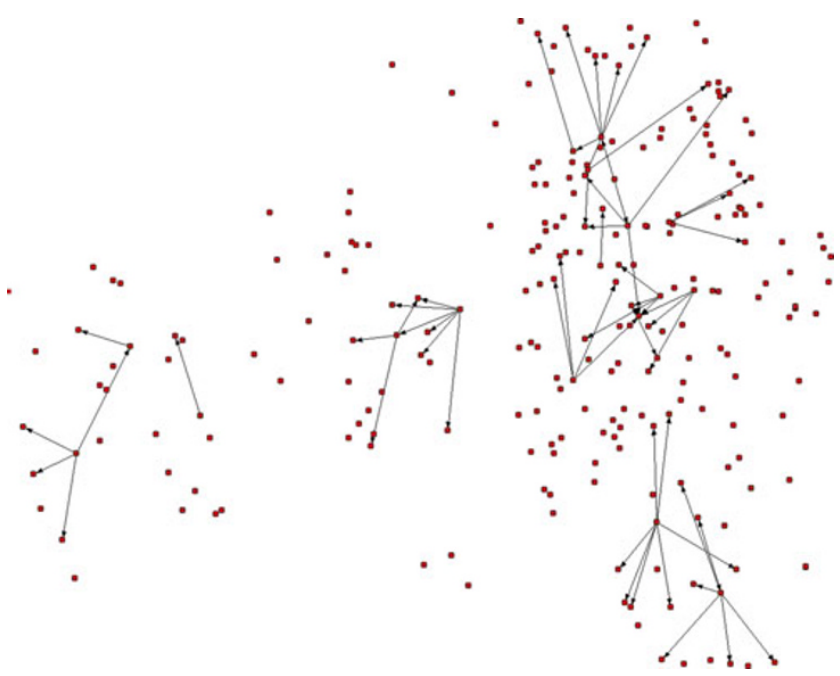

Fig. 2 Cooperation in the development of new ideas in Erfurt, source: Author's data

There are only a few network members engaged in developing new ideas with respect to ESD in Erfurt; many structural holes shape the ESD network.

In contrast, cooperation in the development of new ideas related to ESD works very well in Gelsenkirchen, as seen in Fig. 3.

Figure 3 presents productive relationships in Gelsenkirchen. Gelsenkirchen was chosen as an example here because it demonstrates a nearly perfect cooperation basis, which is very supportive for successful innovation processes. Such results can be used by involved actors in order to disclose strengths and weaknesses and reveal where and how structural conditions enable innovations and development processes.

The network visualizations shown so far are mainly reduced to structural information. Network visualizations can also integrate further actor-related information. Not least,

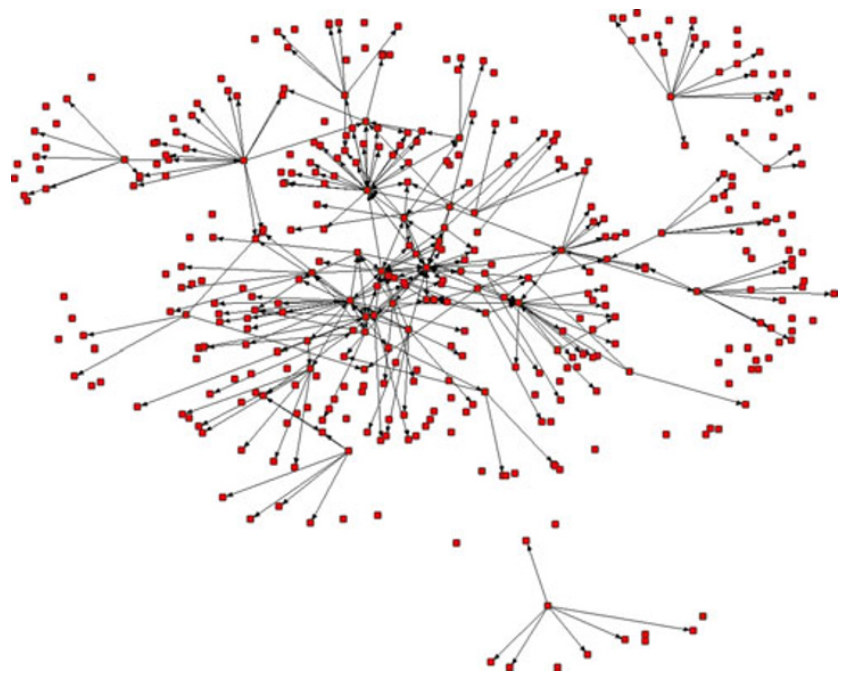

Fig. 3 Cooperation in the development of new ideas in Gelsenkirchen, source: Author's data structural characteristics of social networks, processes of innovation, idea exchange, and trust also depend on the areas of activity to which network members belong. Thus, Fig. 4 integrates some actor-specific information. Nodes represent those people who are actively engaged in the field of ESD in Alheim. The color of the nodes indicates the sector in which the relevant person deals with ESD. The size of the nodes correlates with the individual centrality index. Centrality is measured by the frequency of the responses - the indegree [1, 22]. The more often a person was identified by others, the more central she appears in the picture. The thickness of the connections varies depending on its individual clustering value. While there are two different measures (global and local) for clustering, the local version was used to give an indication of the embeddedness of single nodes [23]. Thus, clustering is defined as the number of common acquaintances; the thickness of the arrow connecting two nodes points to the number of triangular connections.

Figure 4 indicates the central role that people in the field of non-formal education play in Alheim, as measured by how often they were named by other people. Another central position is held by someone in government. The big red node has many incoming and outgoing links, but few triangle relations and thus a low clustering value. Further comparative quantitative studies reveal that despite its high density value, there is little clustering in Alheim. Certainly, the clustering value always depends on the data collection process, but as the study for this article has used the same methodological approach for all five municipal networks, it is possible to compare the municipal clustering values. However, the low clustering value in Alheim is because cooperation beyond institutional borders works very well in this municipality and persons are not always connected to the same partners. The fear expressed by other municipalities, that ESD in Alheim would be dominated by powerful politicians, cannot be confirmed from these results.

In general, quantitative SNA is able to highlight network boundaries and structural characteristics of social networks that are important to understand innovation potential and impediments. It is difficult or even impossible, however, to reveal the causes, motivations, ideas, or perceptions that lie behind such network structures by solely drawing back on quantitative SNA. How, for example, can we explain the central role of one politician in Alheim, while there are many other central persons from non-formal education? What role does this central politician play for the clustering value in Alheim? In order to answer these questions, the study had to draw on further qualitative social network research methods. The researchers thus used a combination of egocentric network maps and semi-structured interviews.

Egocentric network maps are more individual-oriented than quantitative SNA methods. One benefit of network map visualizations lies in their potential for mental or cognitive 


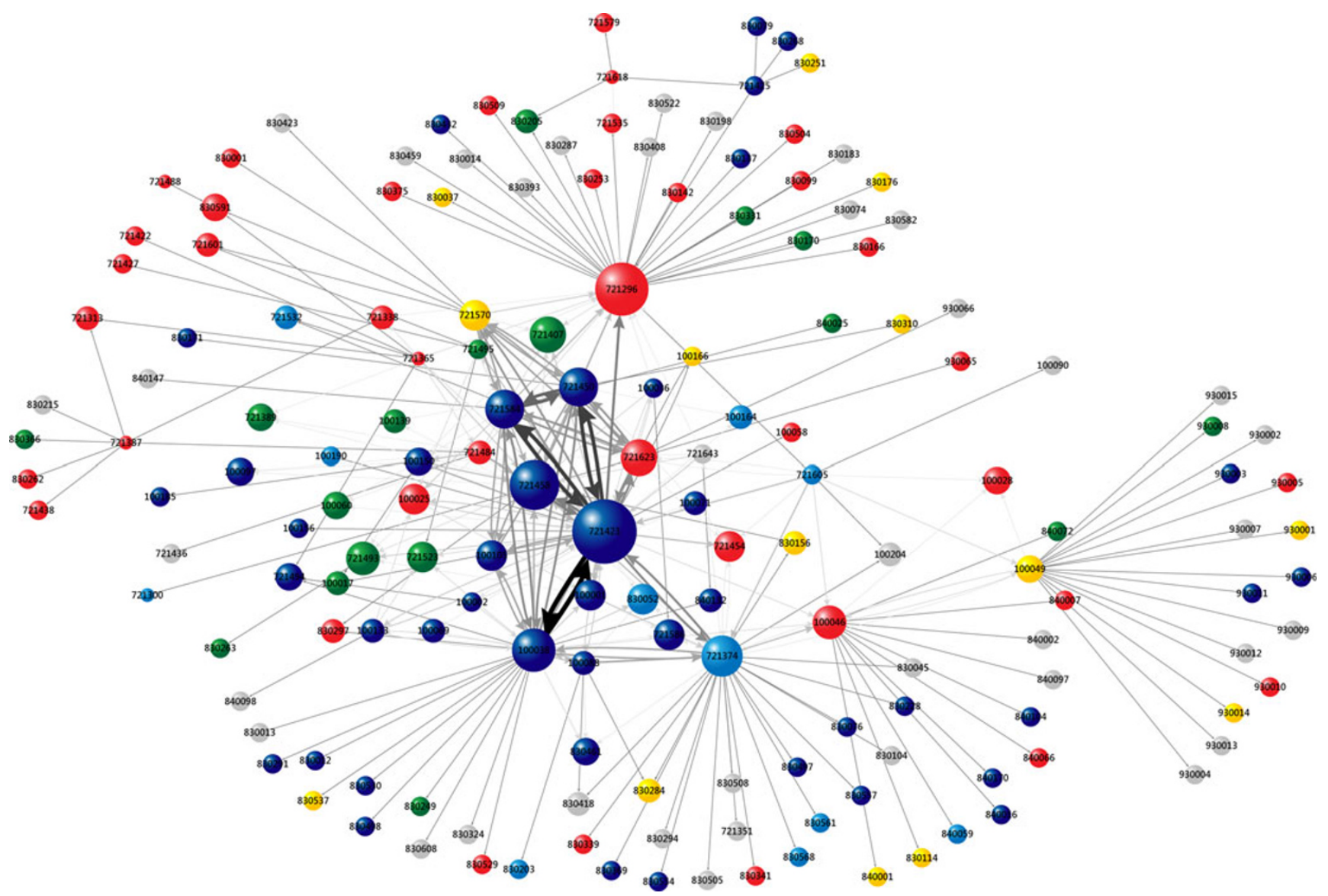

Fig. 4 ESD network in Alheim; color of the nodes according to the area of activity (blue black: non-formal education, red: administration/policy, yellow: NGOs, green: economy, light blue: formal education, orange:

support. Such visualizations are able to promote subjective validations of interview narratives as well as to highlight subjective perceptions, reasons, motivations, and network dynamics. The technique of structured and standardized network maps, which has often been described as the "method of concentric circles" [24], was chosen for this study [25]. Here, network maps are not only aids, but a main purpose of the survey. A sheet with four concentric circles is given to the interviewee. The inner circle represents the ego, that is to say the interviewee. Interviewees are then asked to draw the initials of people important to them personally, differentiated by the degree of emotional proximity or contact frequency. The three circles around the ego represent the emotional closeness or formal distance with respect to her or his alters (or connections). The closer to the ego, the tighter a contact person is perceived by the interviewee. In addition, the circles are divided in parts through lines; each part represents a different area of activity. In this way, interviewees can dedicate their contacts to specific areas of activity, such as civil society, formal education, non-formal education, business or government. The space around ego is structured by both concentric circles that illustrate the closeness of the alters to church, grey: other areas), numbers indicate the IDs of individuals, illustration in cooperation with fas.research, source: Author's data

ego and the area of activity in which alters are engaged for ESD. An essential advantage of the structured and standardized instruments in relation to unstructured techniques lies in the comparability between different network cards (both intrapersonal and interpersonal).

At the same time, the high degree of structuring and standardization constrains the significance of the data obtained. Indications beyond the pre-fixed circles are only possible if interviewers get the opportunity to pose further questions or if interviewees are encouraged to further discuss issues that are not explicitly part of the visualization process. In order to combine both standardization and openness, this study enabled the interviewers to pose further important questions and explore relevant information related to the research aims. The application of egocentric network maps also served as a medium through which interviewees talked about their relationships. In this sense, network maps were integrated into semi-structured interviews in order to generate narratives and disclose relevant relationships and action orientation. In addition, interviewees had the opportunity to choose the categories representing different areas of activity as well as the colors for the visualizations. Thus, the technique implemented in the 
study supported the comparability of the cases, but it was also open for new variables and dimensions related to the specific context.

Altogether 25 network maps and interviews, five in every municipality, were generated. Interviewees were chosen according to their area of activity (to obtain a variance of the cases), their position within the social network, and their centrality indexes. To give an example, Fig. 5 presents the network map of a central politician in Alheim. This network map of Alheim is also chosen to further illustrate the case of Alheim, which was also depicted in Fig. 4. Furthermore, this ESD actor in Alheim possesses a high centrality value according to quantitative SNA.

As Fig. 5 shows, the interviewee mainly distinguishes five areas of activity: civil society, educational institutions, government/administration, business, and persons from trans-regional contexts. In some cases, the politician just wrote down an organization. During the interview, he referred to concrete persons from these organizations. Surprisingly, the sector of government/administration, to which the interviewee himself belongs, is empty: no persons or organizations are indicated. This is also reflected in the visualization based on quantitative network data (Fig. 4), where only one individual from government plays a central role. In a sense, qualitative studies validate quantitative results by showing that the social innovation ESD in Alheim is mainly implemented by actors from non-formal education. At the same time, qualitative results stress that the topic is supported and disseminated by one central politician who bridges structural holes between different sectors. Furthermore, school actors are not represented in the network map, whereas the closest contact persons are from civil society, educational institutions, and business. The great variety of close contact persons from different sectors can be regarded as one reason for the success of the social innovation in Alheim. The central politician in Alheim himself mentions this as playing a significant role. Further actors within the community stress that the ideological foundation and the adoption of ESD would not be possible without this politician. Hence, the establishment of ESD in Alheim can also be traced back to its structural and discursive power and the general trust of ESD actors in this well-connected politician.

The central role of the interviewee in Alheim can be ascribed to the fact that he bridges institutional clusters, supports cooperation beyond government/administration, and combines close cooperation with weak ties in the field of
Fig. 5 Network Map of a central politician in Alheim, anonymized, source: Author's data

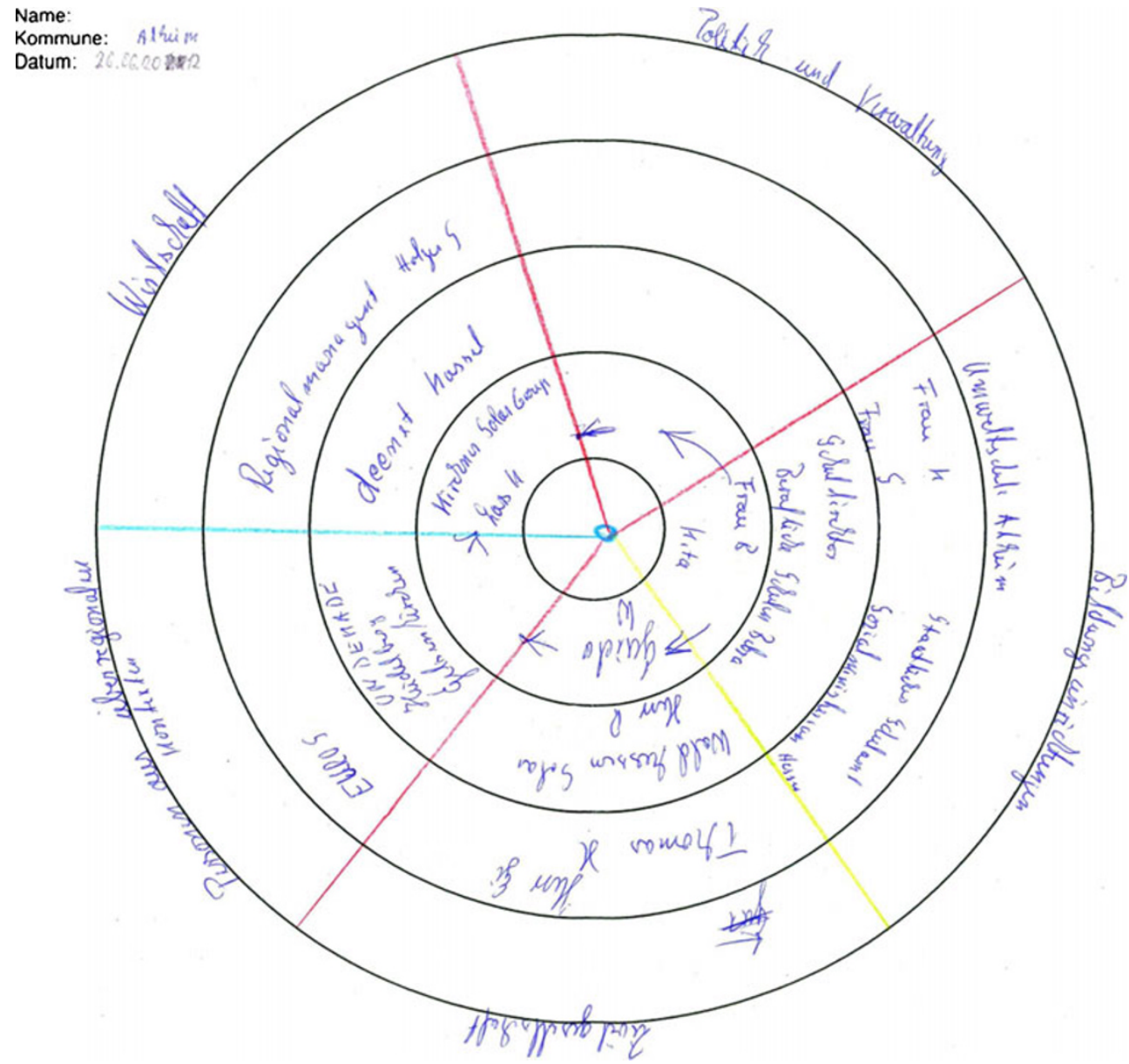


ESD. Furthermore, centrality is not reduced to one person or one sector. Instead, actors from different sectors play a central role in the field of ESD and cooperation between state and non-state actors is very high. In this way, it was possible to develop and realize aims in the area of political accountability in a short space of time. The dense network structure, supported by strong relations between one central politician and actors from other sectors, resulted in the elaboration of an innovative educational plan, composed according to the principles of ESD. At the same time, future strategies should focus on integrating actors from other important areas such as schools. In addition, strategies that foster trans-regional cooperation would be helpful with the diffusion of ESD.

With respect to some of the municipalities, a future strategy that fosters greater participation of stakeholders from other areas of activity, as required by the UN's International Implementation Scheme (IIS) and the National Action Plan of the UN Decade may be helpful in promoting the implementation and diffusion of the social innovation ESD. Business actors and teachers, in particular, complain about not being sufficiently integrated into ESD networks and that the same people always take control and create turf wars. Furthermore, a lack of transparency and information exchange on existing ESD projects was seen. Business actors in these municipalities faced biases from other actors concerned that they ignored ecological and social dimensions of sustainable development. In some municipalities, ESD is mainly concentrated on environmental topics and many ESD actors express reservations about business aims. However, if different sectors are not integrated, it's difficult to achieve a balance between ecological, economic, and social dimensions, as it has been proclaimed by the concept of sustainable development as such.

\section{Conclusion}

This article has explored the role of Social Network Analysis in analyzing and supporting innovation processes. In order to better understand the opportunities of SNA in innovation research, the author presented empirical results of her own quantitative and qualitative research on innovation networks in five German municipalities actively engaged in the field of ESD. The article showed the value of using a combination of both quantitative and qualitative SNA in order to better understand how and why social innovations are implemented and the opportunities to further develop the network.

Quantitative SNA was implemented to analyze the impact of structural characteristics of social networks on the implementation and the diffusion of the social innovation of ESD. It was discovered, for example, that cooperation in the field of ESD mainly takes place within municipalities and that cooperation beyond municipal borders is low and marked by structural holes. Furthermore, it was shown that social networks in the area of ESD are mostly composed of small and dense groups each representing different sets of actors (e.g., local administration, educational institutions, and business) and pursuing different interests and ideas under the umbrella of ESD. Weak ties, on the contrary, are very important in the field of ESD as they are responsible for the diffusion of innovations.

However, structural holes also exist within the municipalities with respect to the quality of the relations. The extreme example of Erfurt illustrated how the development of new ideas can be hampered by structural weaknesses. In contrast, cooperation and innovation development in the field of ESD are regarded to work well in Gelsenkirchen. In Alheim, actors from different sectors are integrated. Most central roles are played by nonformal education actors, whereas one central role is wielded by a politician. In terms of innovation diffusion, Alheim can be regarded as a best practice. Not least, cooperation beyond institutional borders works well and individual clustering values are low: persons are not always connected to the same clusters. Finally, the implementation of ESD in Alheim benefits from strong relations between one well-connected political and actors from other sectors. The central politician connects different areas of activity and promotes the integration of ecological, economic, and social dimensions in terms of sustainable development.

Quantitative techniques of SNA enabled to identify innovation networks, to determine network boundaries, to define actors within the innovation network, and to investigate the network position of actors. Problems of coordination, information, and qualitative relations were discussed. At the same time, quantitative SNA was shown unable to analyze reasons, motivations, and perceptions behind network structure. These issues were then analyzed by using qualitative SNA methods, such as network maps. A combination of qualitative and quantitative SNA techniques may thus prove the most fruitful for innovation research. In order to better understand the role of social networks in the diffusion of social innovations and to generate knowledge related to innovation potential and courses of action, qualitative techniques were used to supplement the quantitative analysis. It was assumed that the costs of information exchange are not only material (money, time), but also social. Conflicts and lack of confidence between actors, for example, may prevent successful innovation diffusion. Qualitative egocentric network maps could validate quantitative results as well as disclose subjective perceptions and orientations. The central position of one politician in Alheim could thus be traced back to its discursive and structural power. Actors in Alheim have great trust in the ideological competences of the well-connected person who supports the establishment of ESD in many sectors. Visualizations with qualitative network maps support the completion of the interview situation with visual representations. Visualized networks can also serve as mental or cognitive assistance. In combination with quantitative results, however, qualitative 
network maps enable us to detect where and how innovations and development processes may be possible due to structural and subjective conditions. Finally, compared to conventional statistical analysis that treat structural and individual levels as separately, analyses and visualizations of network data give us more information about the influence of social relations. SNA enables us to capture the interaction between actors and social context, to better understand how innovations are implemented and diffused, to analyze how and why social or educational change takes place or does not take place, and to disclose opportunities for future strategies.

This contribution has shown that SNA can begin to answer questions related to innovation processes. I hope it will open new avenues for further uses of SNA in innovation and futures research.

Open Access This article is distributed under the terms of the Creative Commons Attribution License which permits any use, distribution, and reproduction in any medium, provided the original author(s) and the source are credited.

\section{References}

1. Wasserman S, Faust K (2009) Social network analysis: Methods and applications. Cambridge University Press, Cambridge

2. Wald A, Jansen D (2007) Netzwerke. In: Benz A, Lütz S, Schimank U, Simonis G (eds) Handbuch Governance. Theoretische Grundlagen und empirische Anwendungsbereich. VS Verlag für Sozialwissenschaften, Wiesbaden, pp 93-106

3. Zafonte M, Sabatier P (1998) Shared beliefs and imposed interdependencies as determinants of ally networks in overlapping subsystems. J Theo Pol 10(4):473-505

4. Hajer M (2009) Authoritative Governance: Policy-making in the Age of Mediatization. Oxford University Press, Oxford

5. Sørensen E, Torfing J (2005) Network governance and post-liberal democracy. Admin Theory Praxis J 27(2):197-237

6. Rogers EM (2003) Diffusion of innovations, 5th edn. Free Press, New York

7. Zapf W (1989) Über soziale innovationen. Soziale Welt 40(1/2):170-183
8. Straus F (2002) Netzwerkanalysen: gemeindepsychologische Perspektiven füür Forschung und Praxis. DUV, Wiesbaden

9. Wolf C (2010) Egozentrierte Netzwerke: Datenerhebung und Datenanalyse. In: Stegbauer C, Häußling R (eds) Handbuch Netzwerkforschung. VS Verlag für Sozialwissenschaften, Wiesbaden, pp 471-483

10. Kolleck N (forthcoming) Qualität, Netzwerke und Vertrauen - Der Einsatz von Netzwerkanalysen in Qualitätsentwicklungsprozessen. Zeitschrift für Erziehungswissenschaft

11. Fischer C (1982) To Dwell among friends. Personal networks in Town and City. The University Press of Chicago, Chicago

12. Burt R (1982) Toward a structural theory of action: Network models of a social structure, perceptions and action. Academic, New York

13. Hennig M (2006) Individuen und ihre sozialen Beziehungen. VS Verlag für Sozialwissenschaften, Wiesbaden

14. Freeman LC (2000) Visualizing social networks. J Soc Struct 11. http://www.cmu.edu/joss/content/articles/volume1/Freeman.html. Accessed 09 July 2013

15. Krempel L (2005) Visualisierung komplexer Strukturen: Grundlagen der Darstellung mehrdimensionaler Netzwerke. Campus Verlag, Frankfurt

16. Castells M (2009) The rise of the network society: The information age: Economy, society, and culture, 2nd edn. Oxford, Wiley-Blackwell

17. Granovetter MS (1973) The strength of weak ties. Am J Soc 78(6): $1360-1380$

18. Granovetter MS (1985) Economic action and social structure: the problem of Embeddedness. Am J Soc 91(3):481-510

19. Burt R (1992) Structural holes. Harvard University Press, Cambridge

20. Burt R (2004) Structural holes and good ideas. Am J Soc 110(2):349 399

21. Podolny JM, Baron JN (1997) Resources and relationships: social networks and mobility in the workplace. Am Soc Rev 62(5):673-693

22. Freeman LC (1979) Centrality in social networks: conceptual clarification. Soc Net 1(3):215-239

23. Watts DJ, Strogatz SH (1998) Collective dynamics of 'small-world' networks. Nature 393(6684):440-442

24. Hollstein B, Pfeffer J (2010) Netzwerkkarten als instrument zur Erhebung egozentierter Netzwerke. http://www.wiso.uni-hamburg. de/fileadmin/sozialoekonomie/hollstein/Team/Hollstein_Betina/ Literatur_Betina/Netzwerkkarten_Hollstein_Pfeffer_2010.pdf. Accessed 09 July 2013

25. Kahn RL, Antonucci TC (1980) Convoys over the life course. Attachment, roles, and social support. In: Baltes PB, Brim OG (eds) Life pan development and behaviour. Academic, New York, pp 253-286 